University of Nebraska - Lincoln

DigitalCommons@University of Nebraska - Lincoln

1987

Satellite-Derived Maps of Snow Cover Frequency for the Northern

Hemisphere

Kenneth F. Dewey

Follow this and additional works at: https://digitalcommons.unl.edu/natrespapers

Part of the Natural Resources and Conservation Commons, Natural Resources Management and Policy Commons, and the Other Environmental Sciences Commons

This Article is brought to you for free and open access by the Natural Resources, School of at DigitalCommons@University of Nebraska - Lincoln. It has been accepted for inclusion in Papers in Natural Resources by an authorized administrator of DigitalCommons@University of Nebraska - Lincoln. 


\title{
Satellite-Derived Maps of Snow Cover Frequency for the Northern Hemisphere
}

\author{
KENNETH F. DEWEy \\ Climatology/Meteorology Program, Department of Geography, University of Nebraska, Lincoln, NE 68588
}

(Manuscript received 30 October 1986, in final form 20 March 1987)

ABSTRACT

\begin{abstract}
A satellite imagery-based Northern Hemisphere snow cover data archive was mapped for the period 196684: The maps were digitized in order to create the first hemispheric, spatially data-continuous climatologies of snow cover. Annual and monthly climatologies were created and compared to several standard or frequently referenced climatologies. Results of this analysis indicate that the satellite-based climatology provides a much more detailed climatology for the higher latitude and highland regions of the Northern Hemisphere. The satellite imagery-based maps, when compared to the historical snow cover climatologies, indicated more extensive highlatitude snow cover concurrent with a northward shift in the southern extent of the climatological snow cover; this results in a narrower snow-transition zone.
\end{abstract}

\section{Introduction}

As noted by Matson et al. (1979), snow cover is a significant climatic index and reflects the dynamic nature of climate. Average snowfall amounts (and resultant snow cover) are related to the average midtropospheric prevailing wind patterns. Therefore, it can be assumed that year-to-year variations in snowfall are manifestations of short-period fluctuations in the prevailing atmospheric circulation.

Numerous researchers (Namias, 1960, 1962, 1985; Kukla and Kukla, 1974; Lamb, 1955, 1972; Dickson and Namias, 1976) have also argued that there is a significant interaction between the extent of snow cover and synoptic-scale atmospheric conditions. The World Meteorological Organization has recommended that "sensitivity studies should be conducted using general circulation models, with special attention being paid to possible feedbacks-for example, between snow cover and temperature" (WMO, 1975, p. 62). Namias $(1962,1963 a, b, 1966,1978)$ for example, has described the positive feedback that occurs when an extensive snow cover becomes established over the eastern part of the North American continent. This feedback is started by some forcing mechanism (such as sea surface temperatures in the North Pacific), or even a random atmospheric perturbation, which ultimately affects the upper-level circulation and positions a trough downstream over eastern North America. This upper-level trough favors polar anticyclones and their deployment southward toward the Gulf of Mexico and the Atlantic Ocean. The extensive snow cover that accompanies this trough refrigerates the polar air masses in their southward transit, and so increases the low-level temperature contrast between these cold air masses and the warmer maritime air masses. Cyclones feed on the enhanced east coast baroclinicity and develop more rapidly. This intensified cyclogenesis adds to the snow cover and assists in the advection of fresh polar air masses southward. This positive feedback will remain in effect until the snow cover disappears with rising spring temperatures, or until other influences on the atmospheric circulation become overwhelming.

Lamb (1972) illustrated an example of this feedback process in Siberia for the summer of 1968. Kukla and Kukla (1974) related the anomalous weather patterns of 1972 and 1973 to the deficit in surface heat exchange which resulted from an increase in the mean annual snow cover. Dey and Kumar (1982) suggested that the increase or decrease of Eurasian spring snow cover could be related to cooling or warming of the midtropospheric air temperatures, which in turn, could possibly control the Indian summer monsoon activity. Cyclonic storm tracks were studied by Heim and Dewey (1984) and it was determined that extensive North American snow cover was related to increased cyclonic activity across the Gulf and southeastern states. Namias (1985) examined the influence of the variation in snow cover during the 1983-84 winter season on regional temperatures and precipitation patterns.

One of the limiting factors in a study of these interactions has been the nature of the snow cover data. Traditionally, snow cover data have been collected at point observations and primarily clustered near midlatitude population centers. It could also be suggested that the many urban airport snow cover observations are not representative of the vast rural areas for which snow cover is interpolated between the various city/ airport locations. Another data source exists for the analysis of snow cover, the Weekly Snow and Ice Cover Charts which have been created from an analysis of 
satellite imagery. It is the purpose of this paper to present this unique database in the form of a climatology of snow cover probabilities for the Northern Hemisphere. These climatologies are then compared to the standard (and traditionally, point observation-based) referenced snow cover climatologies.

\section{A Satellite-based snow cover archive}

In November 1966, the first satellite-derived Northern Hemisphere Weekly Snow and Ice Cover Chart was produced by the National Environmental Satellite Service (NESS) of NOAA. Satellite data have been available at all times since that origin date. The snow cover data, which have been mapped on a 1:50000000 polar stereographic projection of the Northern Hemisphere, have come from a variety of satellites and sensors which have been subject to instrumental variation, degradation, drift, and variation in subpoint resolution (ranging from 1 to $3.7 \mathrm{~km}$ in the visible range). However, the impact of these factors on mapping continental snow cover has been considered negligible (Matson and Wiesnet, 1981).

There have been several analysts responsible for the creation of these charts since their inception, and they have all been trained within the same branch of NESS, the Synoptic Analysis Branch (SAB). The procedure behind the creation of the snow cover maps consists of daily collecting all the visual band imagery (received during the previous day) and adjusting the snow boundary of the previous week's chart. Each area of the new chart is, therefore, the latest cloud-free snow observation of that particular area of the world. If an area remains cloud-covered for several days, the analysis of snow cover for that area will be several days old. If the area remains cloud-covered for the entire week, the previous week's analysis is carried over to the new chart. As a last step, the analyst should compare the chart with surface synoptic reports to check for errors or to confirm drastic changes in snow cover which can result from a new snowfall or rapid snow melt (Matson and Wiesnet, 1981).

Two other factors could potentially influence the decision of whether or not there is snow cover represented on the satellite imagery: forest canopy and highlatitude solar illumination. Fortunately, no attempt has been made to estimate snow depth in the forest canopy, for that task would be quite impossible using standard visual imagery. However, although there is reduction in brightness associated with a forest region, during most of the snowy season the imagery will pick up enough reflectivity of snow from the forest structure, as well as open lakes, meadows, etc., that the existence of a snow cover can be detected. This phenomenon was, for example, illustrated for the Boreal forest region of Southern Canada (Baldwin, 1985). It is true that in late spring there could be melting piles of snow which are unobservable beneath the canopy of a forest, but this would represent an extremely small portion of the Northern Hemisphere snow cover.

In winter, much of the far northern latitudes remain in total darkness or near darkness. Consequently, the visual band sensors on the satellite would be inoperative in these areas around the pole. According to Matson and Wiesnet (1981), the area of "darkness" at its maximum (winter solstice) can extend as far south as $55^{\circ} \mathrm{N}$ lat. Fortunately, as the region of darkness spreads equatorward, the snow line is well south of the darkness region. In digitizing the maps (Dewey and Heim, 1982; Heim and Dewey, 1984), only one weekly map had an area of apparent open snow cover intersecting the "darkness" circle, and that was in central Norway. Surface climatologies also seem to verify that snow cover is persistent throughout this region of polar darkness, except for very narrow coastal regions which are below the resolution of this snow cover climatology.

The quality of the global archive has also been influenced by inconsistent mapping of the Himalayan snow cover for the period 1966-74 (Dewey and Heim, 1982). Therefore, caution must be utilized in the interpretation of the snow cover boundary in this area of the Northern Hemisphere.

Kukla and Robinson (1979) analyzed the accuracy of these satellite-derived snow cover charts by comparing them with an independent daily analysis of snow cover based on satellite data and ground station reports for the United States. Two major conclusions were derived from their study: 1) the differences which were small (usually less than $10 \%$ ) were slightly smaller in more recent charts; and, perhaps most significantly, 2) the accuracy of the NOAA/NESS weekly charts is adequate for climate-related studies on a continental or hemispheric scale (Kukla and Robinson, 1979; Matson and Wiesnet, 1981). The most serious limitation in the use of the week-to-week North American snow cover maps is the somewhat reduced quality of the autumn charts (as noted in section 3).

The satellite-derived snow cover data offers the primary advantage of a globally spatially continuous data archive which provides the first extensive snow cover information for mountainous high latitudes, and sparsely populated regions of the world. Because the maps have been digitized (using the same grid which is utilized by the National Meterological Center in the creation of their various forecast products) a series of maps can be mathematically (as opposed to subjectively) combined, resulting in several climatological maps (averages, frequencies, anomalies, etc.). Although this snow cover data record is relatively short (spanning just short of two decades), it should be noted that this is the most extensive (spatially) database available for snow cover.

\section{Digitization of data and analysis procedures}

The study period for this research effort begins with the first week in November 1966 and runs through the 
last week in October 1984. It would be ideal if the snow cover archive existed for a standard period of time, such as 30 yrs; however, consistent and hemispheric satellite coverage necessary for the preparation of the weekly snow cover charts did not exist prior to this starting date. It should also be noted that a weekly time frame for snow cover data eliminates the problem of data voids resulting from cloud cover lingering over an area for several days. It is also doubtful whether a shorter period of (for example, a day or two) snow cover would have a significant influence on the atmospheric circulation and/or climate. Occasionally, cloud cover would preclude observation of snow cover across a region for several days. In these instances, if the majority of the days for that week were observable, and were snow covered, the entire week was still classified as a "snow-covered" week. On several occasions extensive cloud cover would persist for longer than a week over a given region, and would mask the weekto-week changes in the snow line. In these instances, the analyst would carry over the snow cover for that region to the next week. The obvious implication in these situations is that the ground stations could be "observing" or reporting the establishment of snow cover prior to the satellite analysis. As indicated by Kukla and Gavin (1983), this bias was primarily an autumn occurrence. Fortunately, this problem is less apparent for North American than European snow cover, where the satellite-derived maps utilized in this study indicated regional European cloud covers that persisted for as long as 3 weeks. Although this potential observation bias exists (especially during the autumn), it was hoped that the North American occurrences were geographically and temporally limited enough that this unique data archive could still be compared to several existing ground station climatologies.

The weekly snow cover charts were digitized (Fig. 1) using an 89 by 89 element matrix covering the entire Northern Hemisphere (except for portions of the tropics). Any grid box that was $50 \%$ or more covered by snow was considered to be completely covered. This specific grid was chosen so that the gridded data in this research project would be directly compatible and usable within the many forecast models run on the NMC mainframe computer. The grid is also a standard grid frequently utilized within climate models. These weekly digitized charts were then combined to create average weekly, monthly, seasonal, and annual snow cover frequency maps. The annual frequencies consisted of a map for each snow cover year (September-August), as well as an overall or "master" frequency map of all snow cover years combined. An example of one of these generated frequency maps is presented in Fig. 2 for week number 50 . The number of days in a year (365.25) is not exactly divisible by 7; consequently, the dates for each weekly chart vary slightly from year to year. Week number 50 , for example, has a median date of 12 December, with a starting date varying from 6-9
December over the study period. Additional detail on this digitization process is presented by Dewey and Heim (1982).

\section{Snow cover frequencies}

\section{a. Annual snow cover climatologies}

All of the weekly snow cover charts were combined to create an overall or "master" frequency of snow cover for the Northern Hemisphere (Fig. 3a). This figure represents the approximate percentage of the time during an entire year that snow cover could be expected. It should be recognized that snow cover has existed equatorward of the " 0 " percent line. However, the snow cover, when it has occurred for only a day or two (and the remaining portion of the week was "observable" by satellite and did not have a snow cover), was not classified as a "week-long" snow cover. If a short-term snow cover was masked by persistent cloud cover for the remainder of the week, and risked being classified as a "week-long" event, the analysts would check surface observations across the lower-latitude regions (Matson and Wiesnet, 1981). Therefore, almost all of the "deep south" transient snow covers do not show up in this weekly snow cover archive.

Two other "standard" and frequently referenced annual snow cover climatologies are included for comparison with the satellite-derived climatology (Fig. 3b, Lamb; and 3c, WMO). The obvious difficulty in comparing these climatologies is the difference in the time periods utilized for each climatology. Figure $3 b$ is based upon (i) the average number of days with the ground (at point observations) more than half covered with snow and (ii) the time period of 1900-50. Figure 3c, although frequently referenced as Lockwood (1979), actually had its origin in a Global Atmospheric Research Program (GARP) study conducted under the auspices of the World Meteorological Organization (WMO, 1975). This WMO (1975) climatology was based upon a study published by the U.S.S.R. Academy of Sciences (Moscow) in 1960 (and unavailable within the United States library system). The only information provided within the WMO (1975) publication is the indication that the global snow cover map was created from two decades of surface observations prior to 1960 . The most obvious difference between the three climatologies is the increased detail in the mountainous region of North America and Asia, as illustrated in the satellite-derived climatology. The equatorward limit of snow cover persisting for at least 1 week passes through a fairly well-populated zone in the Northern Hemisphere (with numerous observation locations); therefore, it is not surprising to find close similarity in the positioning of the " 0 " percentage isoline in all three climatologies. The WMO climatology has a much larger area of Siberia enclosed by the $70 \%$ isoline than the Lamb climatology, and the satellite-derived climatology offers a spatial compromise between these 


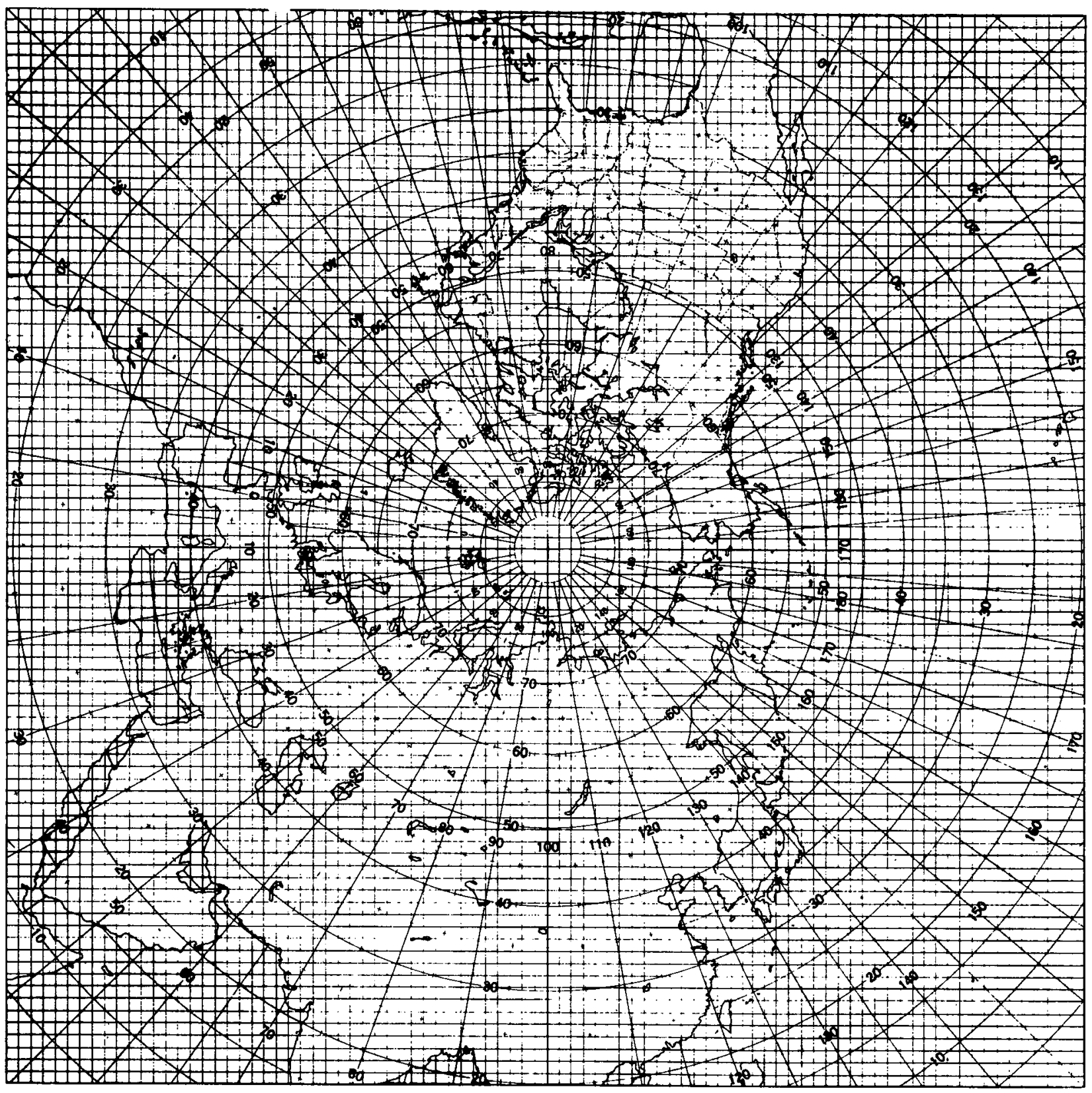

FIG. 1. Grid utilized for the digitization of the snow cover maps.

two climatologies for that region. It is uncertain whether the WMO or satellite-derived climatology is the best for this region (due to the nonconforming time period); however, it might be concluded that either one is superior to the Lamb climatology. In fact, of the three climatologies, the Lamb climatology provides the most generalized pattern (especially in northwestern North America) of snow cover frequencies.

\section{b. Monthly snow cover climatologies}

Another standard climatology of snow cover is Dickson and Posey's (1967) series of monthly Northern
Hemisphere snow cover probabilities. This climatology has remained as a standard in the literature and has appeared in numerous textbooks illustrating, for example, normal winter snow cover and probabilities of a "white Christmas." Dickson and Posey (1967) computed snow cover probabilities using a wide range of data (for example: United States, a network of stations for the period 1931-50; Canada, 1940-60; Japan, from an Atlas with no specific dates; and pre-1915 data for most of the Soviet Union). These authors cautioned that secular climatic changes may limit the usefulness of their maps. Although the satellite-derived snow cover 


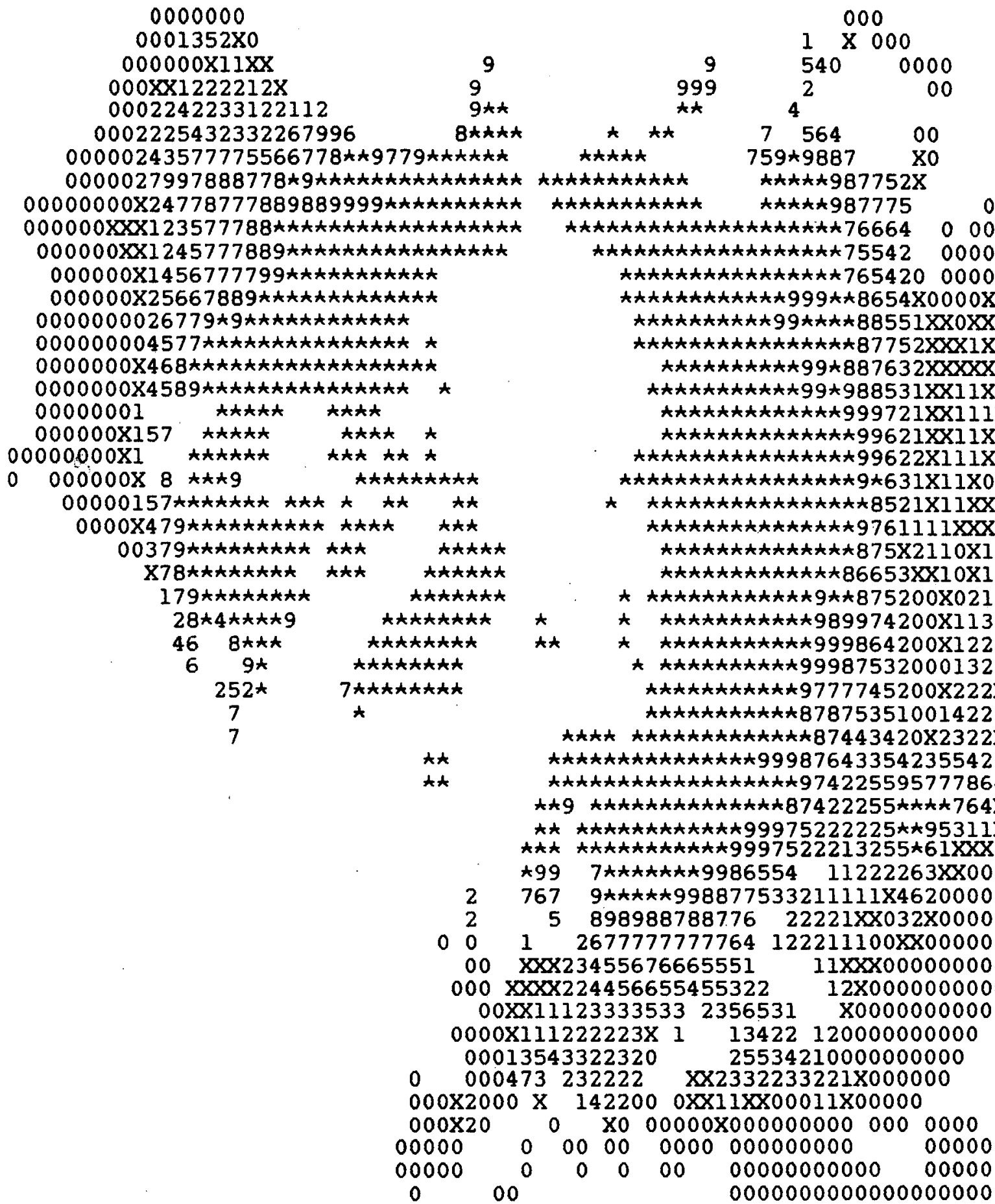

FiG. 2. Snow cover frequency map, Northern Hemisphere, week no. 50. Legend: $0=$ no snow; $X=01-09 \% ; 1=10-19 \% ; 2=20-29 \%$; $3=30-39 \% ; 4=40-49 \% ; 5=50-59 \% ; 6=60-69 \% ; 7=70-79 \% ; 8=80-89 \% ; 9=90-99 \% ;$ asterisk $=$ always snowcovered.

archive is fairly short compared to most standard climatologies, at least this data archive offers the advantage of a fairly consistent spatial and temporal dataset (with the one well-documented limitation of the pre1972 charts being less accurate than the later ones).
The Dickson and Posey (1967) monthly maps were based upon observations corresponding to the last day of each month for September through May. Therefore, even though the digitized archive could actually be mathematically manipulated to provide a true 


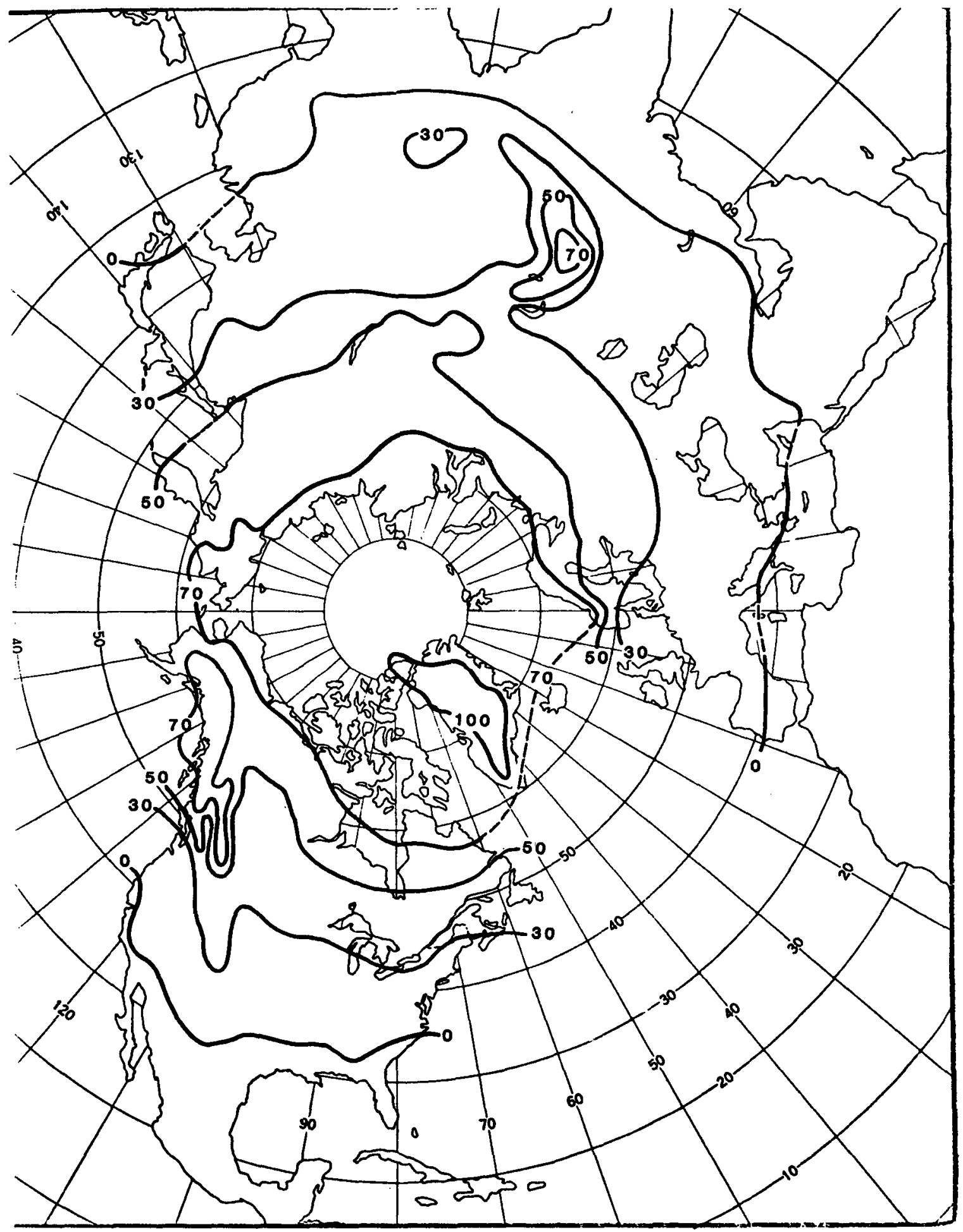

FIG. 3. Average annual frequency of snow cover (in percent): (a) Dewey, (b) Lamb and (c) WMO.

"monthly" climatology, the average of the last week of each month was chosen for comparison to this other "monthly" climatology. Five comparisons are included here for analysis (September, November, January, March, and May). The average snow cover for each month, based upon the satellite-derived data archive 


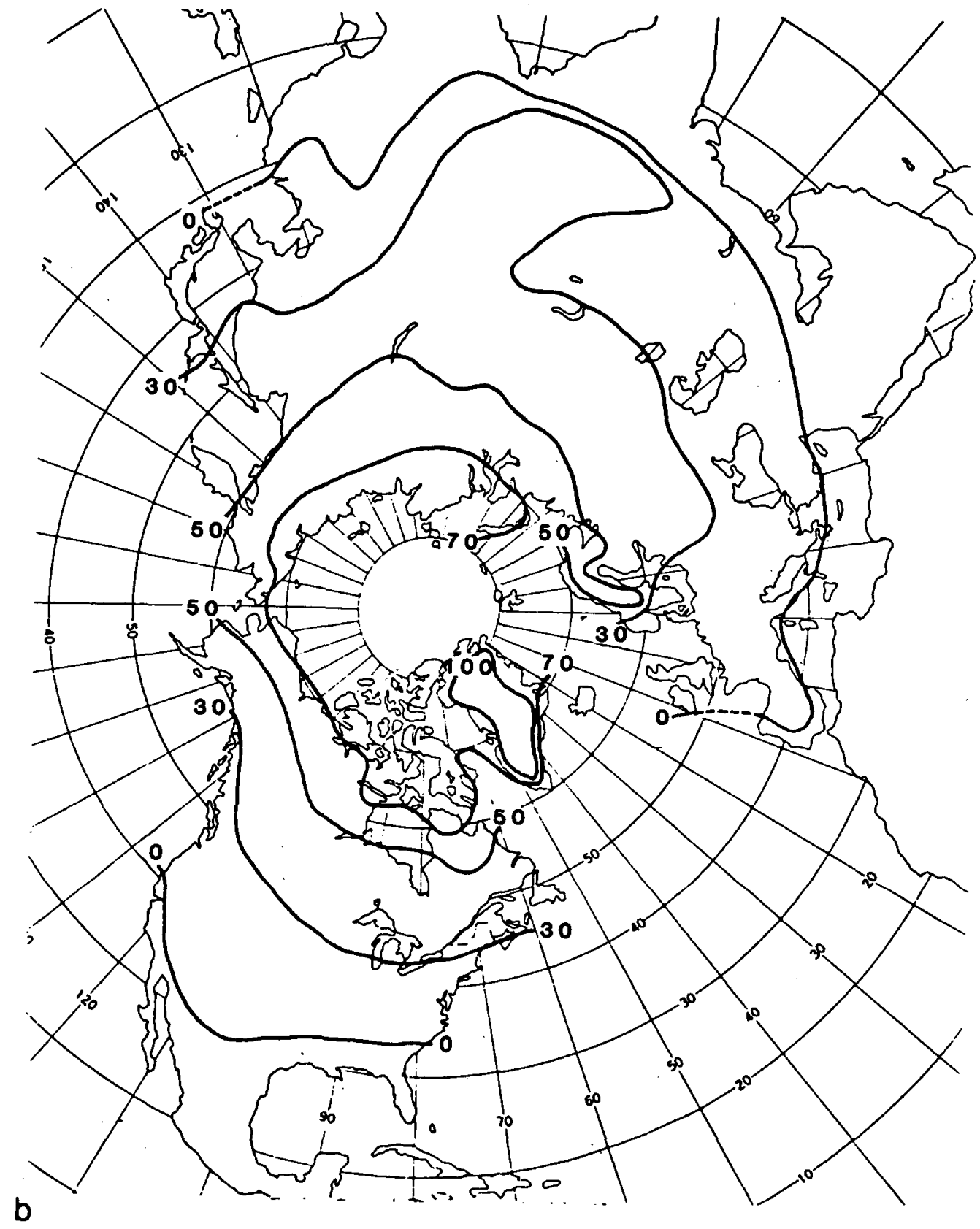

Fig. 3. (Continued)

is listed in Table 1 for both North America and the Northern Hemisphere. An examination of this table reveals that the increase in hemispheric snow cover normally begins in September, peaks in January, and decreases rapidly through late spring with very little variation in the remaining snow cover during JulyAugust. These five comparative snow cover frequency maps encompass the entire snow cover "season" for the Northern Hemisphere.

The satellite-based snow cover climatology compared to the Dickson and Posey climatology for the end of September is mapped in Fig. 4. The southern extent of possible snow cover in North America during this research time period is considerably further north than in the Dickson and Posey map. It might be concluded, therefore, that the onset of the snow cover season during the last two decades has been delayed by several weeks when compared to the 1930-60 time period utilized by Dickson and Posey. There is evidence that this same phenomenon has occurred in Asia as well; however, the latitudinal difference in Asia appears to be around 5 deg compared to the $10 \mathrm{deg}$ latitudinal 


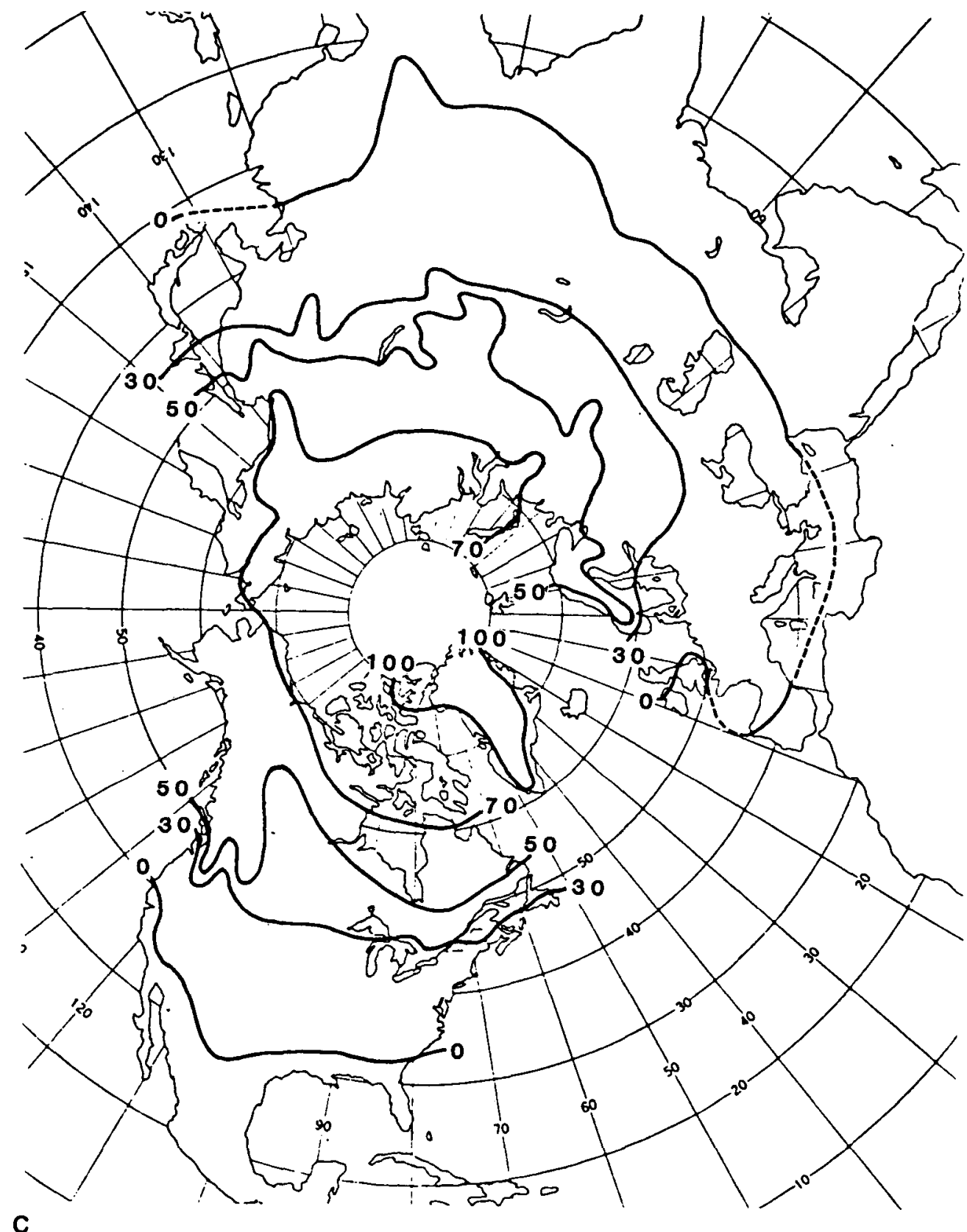

Fig. 3. (Continued)

difference in North America. It could also be suggested that the previously mentioned problem of late recognition of snow on the satellite charts may have had a small influence on this phenomenon. In contrast to this, though, is the increased area with a frequency exceeding $50 \%$ in northern Asia and an increased area of $100 \%$ snow cover frequency in North America during the satellite-derived data period. One other striking contrast exists: the satellite climatology provides much greater detail for the snow cover climatology of the
Southern Asia region and places a frequency of greater than $50 \%$ in several highland areas which receive no snow cover according to the Dickson and Posey climatology. This is not surprising, considering that the Dickson and Posey climatology consisted of ground stations located at low elevations.

A comparison of the November snow cover climatologies (Fig. 5) indicates a general agreement in the possible southern extent of snow cover in North America; however, there are several areas of disagreement 
TABLE 1. Northern Hemisphere monthly snow cover areas $\left(\times 10^{6} \mathrm{~km}^{2}\right)$. November 1966-June 1985.

\begin{tabular}{lllll}
\hline & Maximum (yr) & Minimum (yr) & Average & Standard deviation \\
\hline Jan & $51.0(1979)$ & $41.2(1981)$ & 46.2 & 2.6 \\
Feb & $52.8(1978)$ & $40.1(1970)$ & 46.4 & 3.0 \\
Mar & $43.5(1971,78,79)$ & $37.0(1970)$ & 41.0 & 1.9 \\
Apr & $36.3(1979)$ & $27.6(1968)$ & 31.7 & 2.3 \\
May & $24.6(1978)$ & $17.2(1968)$ & 21.2 & 1.8 \\
Jun & $15.5(1976)$ & $7.5(1984)$ & 5.5 & 1.9 \\
Jul & $8.5(1967)$ & $3.6(1982)$ & 3.9 & 1.3 \\
Aug & $5.3(1980)$ & $2.7(1970,84)$ & 5.2 & 0.8 \\
Sep & $9.9(1972)$ & $2.6(1970)$ & 17.7 & 1.6 \\
Oct & $31.6(1976)$ & $7.4(1968)$ & 33.5 & 5.7 \\
Nov & $37.6(1973)$ & $29.5(1979)$ & 41.9 & 2.0 \\
Dec & $45.6(1973)$ & $37.1(1969)$ & 25.5 & 2.5 \\
Annual & $28.3(1978)$ & $23.5(1970)$ & & \\
\hline
\end{tabular}

in Eurasia. The southern extent of possible snow cover for the later satellite time period is about $5^{\circ}$ lat further north in Europe, and over $15^{\circ}$ further north in the $100^{\circ}-120^{\circ}$ long region of Asia. This difference, as in Fig. 4 , could be related again to a possible climate variation of more recent delays in the onset of the winter snow cover. (However, some caution must be exercised due to the poorer quality of the autumn satellite interpretation.) The $50 \%$ frequency isoline is similar in both maps, except for the Rocky Mountain region which appears to have more frequent snow cover during the satellite data period. The possibility that snow cover has increased in frequency throughout the mountainous western states must be considered, in conjunction with the possibility that the sparse surface network of earlier climatologies merely undermeasured the snow cover frequency. The placement of the $50 \%$ isoline in Eurasia is similar for both maps, with the exception, as was noted for September, that the satellite archive provides quite a different interpretation of the snow cover across southern Asia. It is interesting to note that the Dickson and Posey map placed a large area exceeding $50 \%$ centered on $35^{\circ} \mathrm{N}$ long and $90^{\circ} \mathrm{E}$ lat. The digitized satellite data for this area indicate only a $10-30 \%$ frequency of snow cover. The satellite data, however, indicate that there is a large area exceeding $50 \%$ and a smaller area of $100 \%$ snow cover near $75^{\circ} \mathrm{E}$ long and $35^{\circ} \mathrm{N}$ lat. This satellite-derived snow cover-maximum occurs in an area that was mapped as 0 to $10 \%$ frequency by Dickson and Posey. These large differences are undoubtedly the result of comparing continuous satellite data with the sparsely located surface observations in this portion of the world. No inferences on change in snow cover climate should be inferred from this specific difference in mapped values. The $100 \%$ isoline is, however, further south in the satellite data-derived maps of North America and Asia. There is also an inexplicable region of snow cover being less than $50 \%$ over Hudson Bay in the Dickson and Posey interpretation. The variation between the two maps in Eurasia consists primarily of the satellite-derived $100 \%$ snow cover occurring $5^{\circ}$ lat further south from $80^{\circ}$ to $100^{\circ} \mathrm{E}$ long and $5^{\circ}$ lat further north from $115^{\circ}$ to $135^{\circ} \mathrm{E}$ long. This is an area of sufficient surface observations, so it might be concluded that the satellite data period might be representing a true climatic variation in this portion of Asia.

The peak of the Northern Hemisphere snow cover as mapped in Fig. 6 (which illustrates January snow cover) indicates for North America a larger area of $100 \%$ frequency of snow cover and, at the same time, a more northerly limit of snow cover extent during the satellite data period. A direct comparison of the snow cover transition zone for North America $(0-100 \%$ frequency) indicates that the width of this zone has decreased by $25-50 \%$ since the $1930-60$ time period. This same phenomenon, although to a lesser degree, appears to have also occurred across Eurasia. The placement of the $0 \%$ and the $100 \%$ contour line can be determined by a single event during an unusually anomalous year; therefore, this apparent contraction of the snow transition zone may be partly the result of the difference in the sample periods for both datasets. The $50 \%$ isoline is in general agreement between the two climatologies. Of the various maps presented here, this figure illustrates the least difference in the two interpretations of the south-central Asia snow cover frequencies. This is, most likely, a reflection of the climatology of highly persistent snow cover this time of year for this region.

By the end of March, the snow cover frequencies have rapidly dropped throughout the Northern Hemisphere. The persistent snow cover, as mapped in Fig. 7 , has now retreated to central Canada northward and generally north of $55^{\circ}$ lat in Asia. A consistent difference between the two climatologies appears again; the southern extent of the snow boundary this time of year is further north during the more recent satellite data period. In the United States, this difference is most notable over the central Great Plains. In Europe, Dickson and Posey have the southern extent of the snow line encompassing France and Germany, which is south of the boundary in the satellite analysis. The 


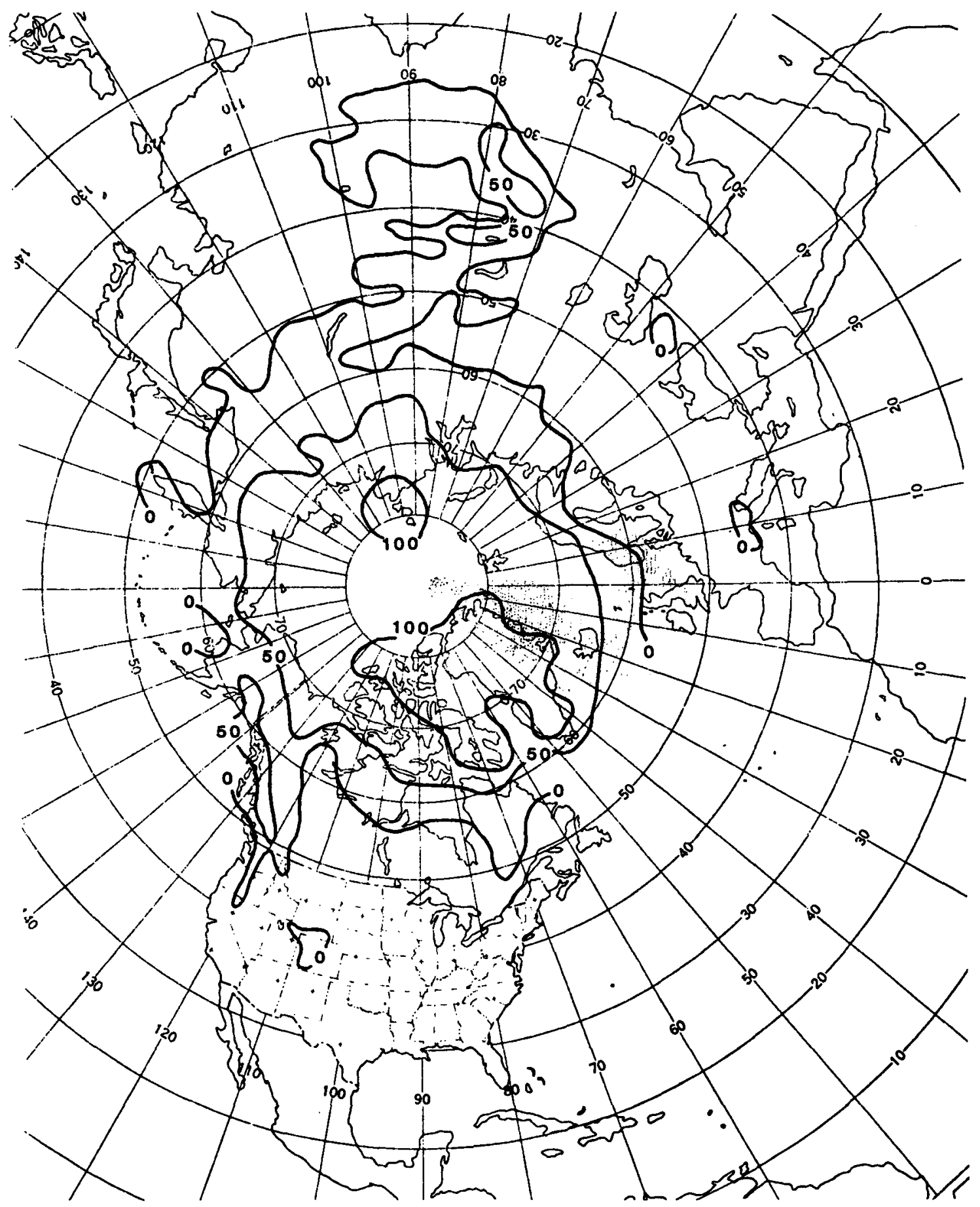

FIG. 4. Average frequency of snow cover (in percent) for the end of September: (a) Dewey-satellite imagery derived; (b) Dickson and Posey-surface observations.

largest difference occurs in the area between 100 and $120^{\circ} \mathrm{E}$ long, where the satellite southern extent of snow cover is at $40^{\circ} \mathrm{N}$ lat and the earlier climatology puts the southern extent at $27-32^{\circ} \mathrm{N}$ lat. Much of the data from this area for the Dickson and Posey climatology came from the earlier part of the century. The more extensive snow cover may then be a function of the colder average temperatures during that time span. As illustrated in the other figures, it also appears that the snow transition zone has decreased in size, with much 


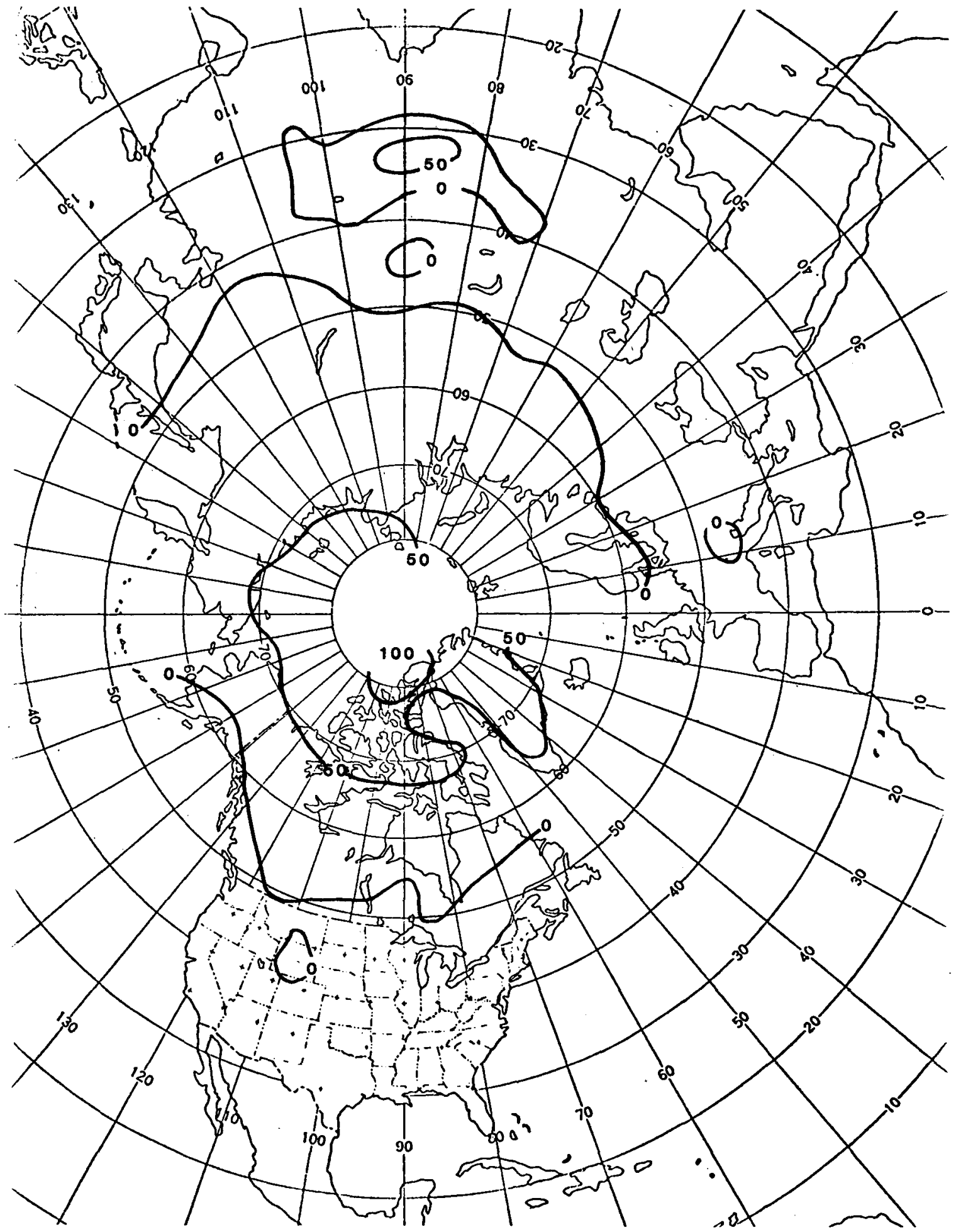

FIG. 4. (Continued)

of the $100 \%$ frequency isoline being further south throughout the Northern Hemisphere during the satellite data period. In eastern North America, for ex- ample, the earlier climatology places the $100 \%$ frequency across Northern Ontario and James Bay, yet the satellite analysis places it across the northern Great 


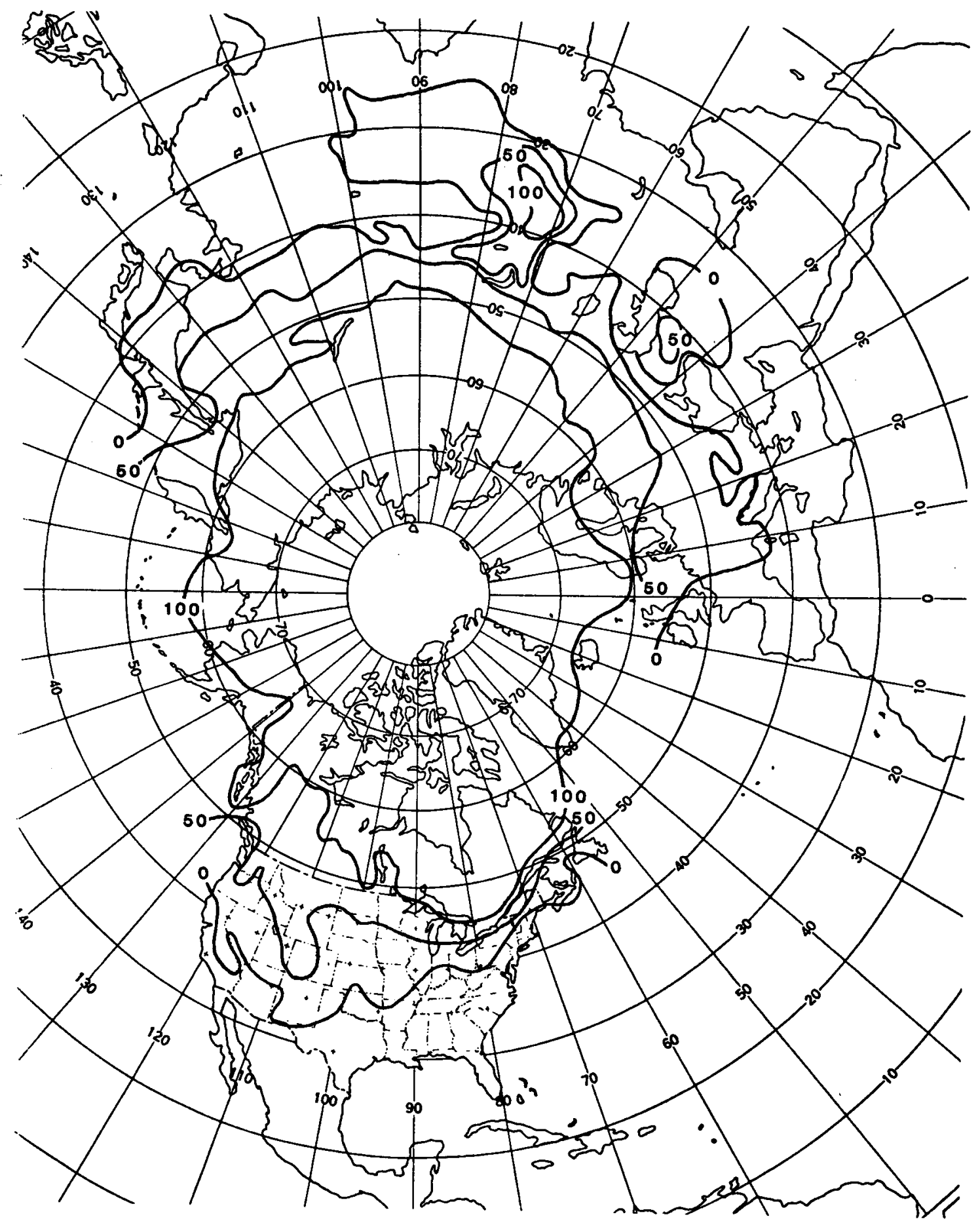

FIG. 5. As in Fig. 4, except for the end of November.

Lakes and south-central Ontario. It is also significant to note that the satellite-derived data locates a region exceeding 50\% frequency and approaching $100 \%$ frequency in an area $\left(40^{\circ} \mathrm{N}\right.$ and $\left.70^{\circ} \mathrm{E}\right)$ which the earlier Dickson and Posey climatology analyzes as having no snow cover to slightly more than zero frequency of snow cover.

The end of May snow cover frequency is included to illustrate the climatology of snow cover toward the end of the hemispheric snow cover "season." As illus- 


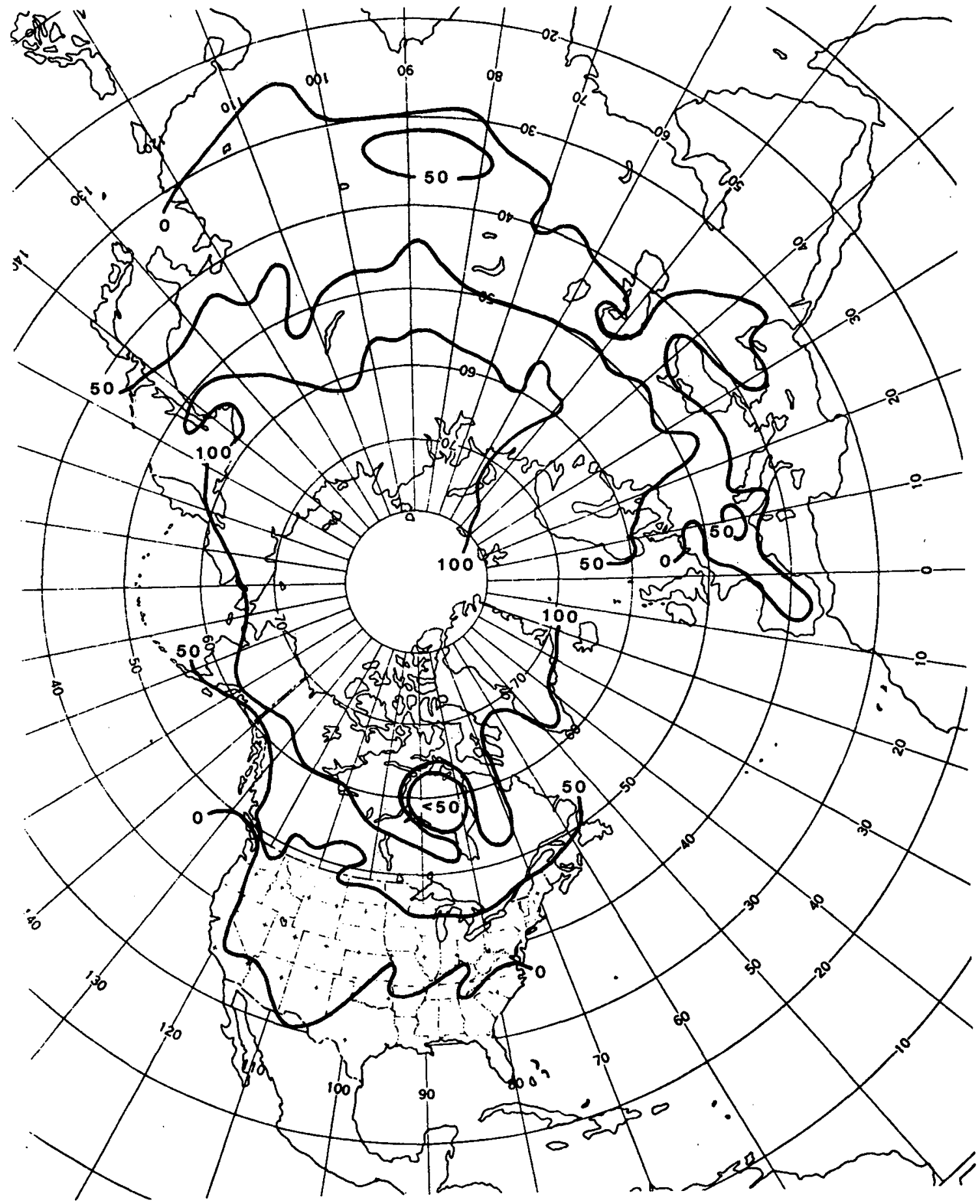

FIG. 5. (Continued)

trated in Fig. 8, the satellite data archive has created a much more detailed analysis in the mountainous region of North America. The earlier climatology indicates a total lack of snow cover in the mountainous region from the Alaska-Yukon region down through the states, yet the satellite analysis indicates regions of 50-
$100 \%$ snow cover frequency. The satellite data archive places the southern boundary of the snow cover probability about $5^{\circ}$ lat further north in Manitoba, yet at about the same location across Ontario, Quebec and the Maritimes. It is also evident that the more recent climatology of snow cover indicates a more persistent 


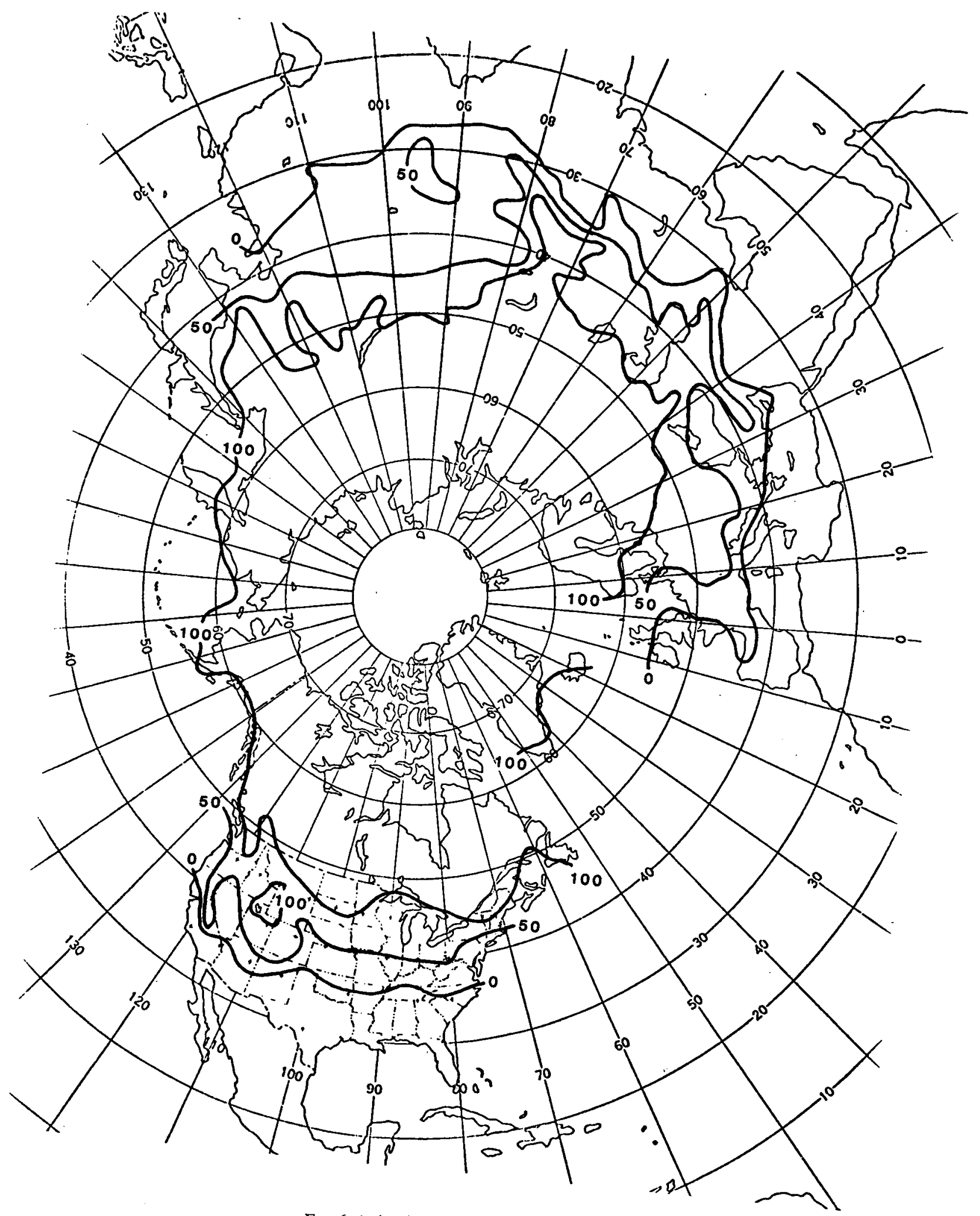

FIG. 6. As in Fig. 4, except for the end of January. 


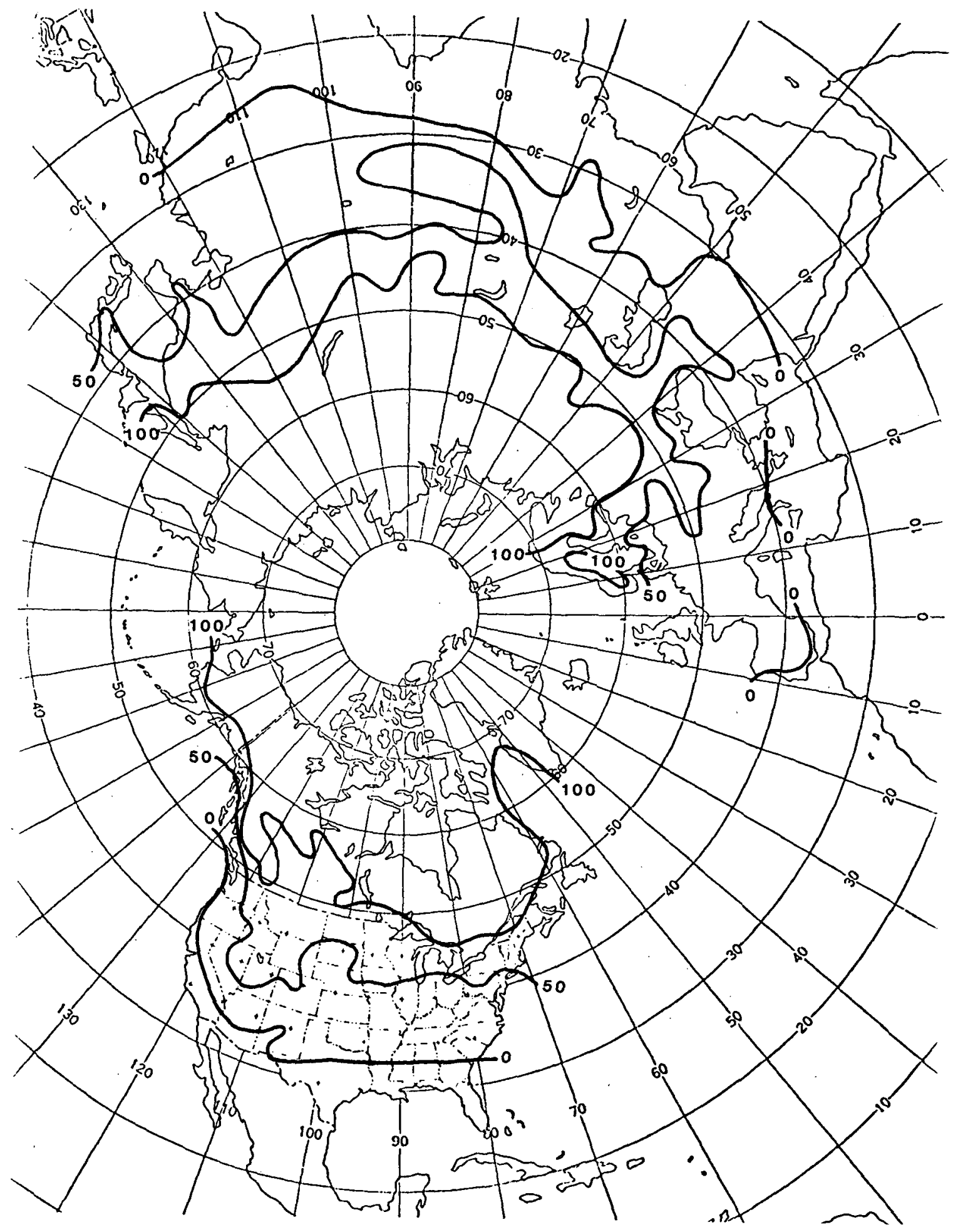

FIG. 6. (Continued)

snow cover has existed during the last few decades across the Arctic Archipelago. The recent more frequent snow cover in the Arctic during May also is ap- parent in Asia, where the satellite analysis shows a much larger area covered by a $100 \%$ frequency of snow cover. It should be noted, however, that the southern 


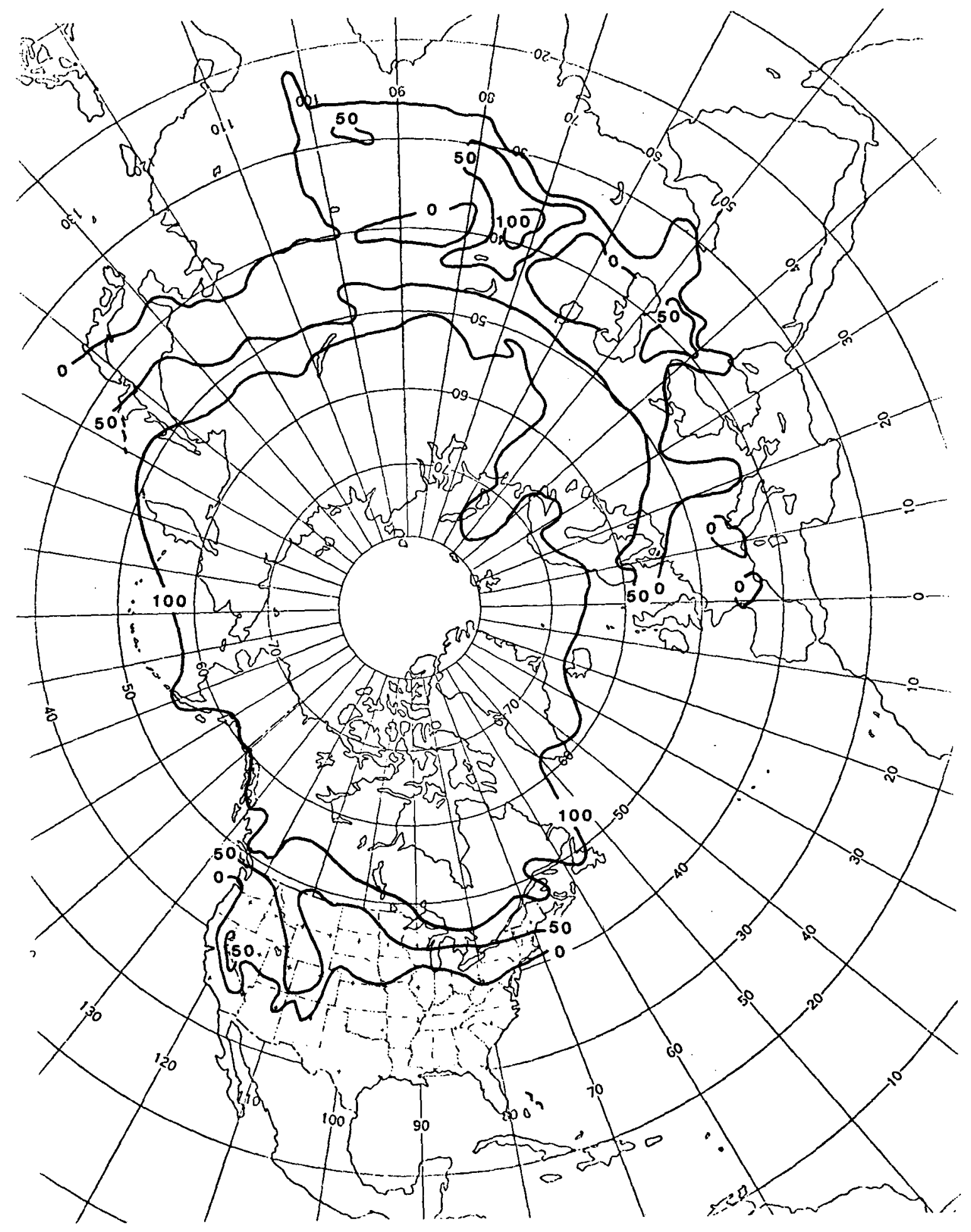

FIG. 7. As in Fig. 4, except for the end of March.

extent of snow cover probability using the satellite-derived data is further north in western and eastern Asia, with again a much higher frequency in the highlands region of $35^{\circ} \mathrm{N}, 75^{\circ} \mathrm{E}$. There are no summer Dickson and Posey maps; therefore, it cannot be determined whether this recent, more extensive Arctic snow cover is a phenomenon that persists through June, July, and August. 


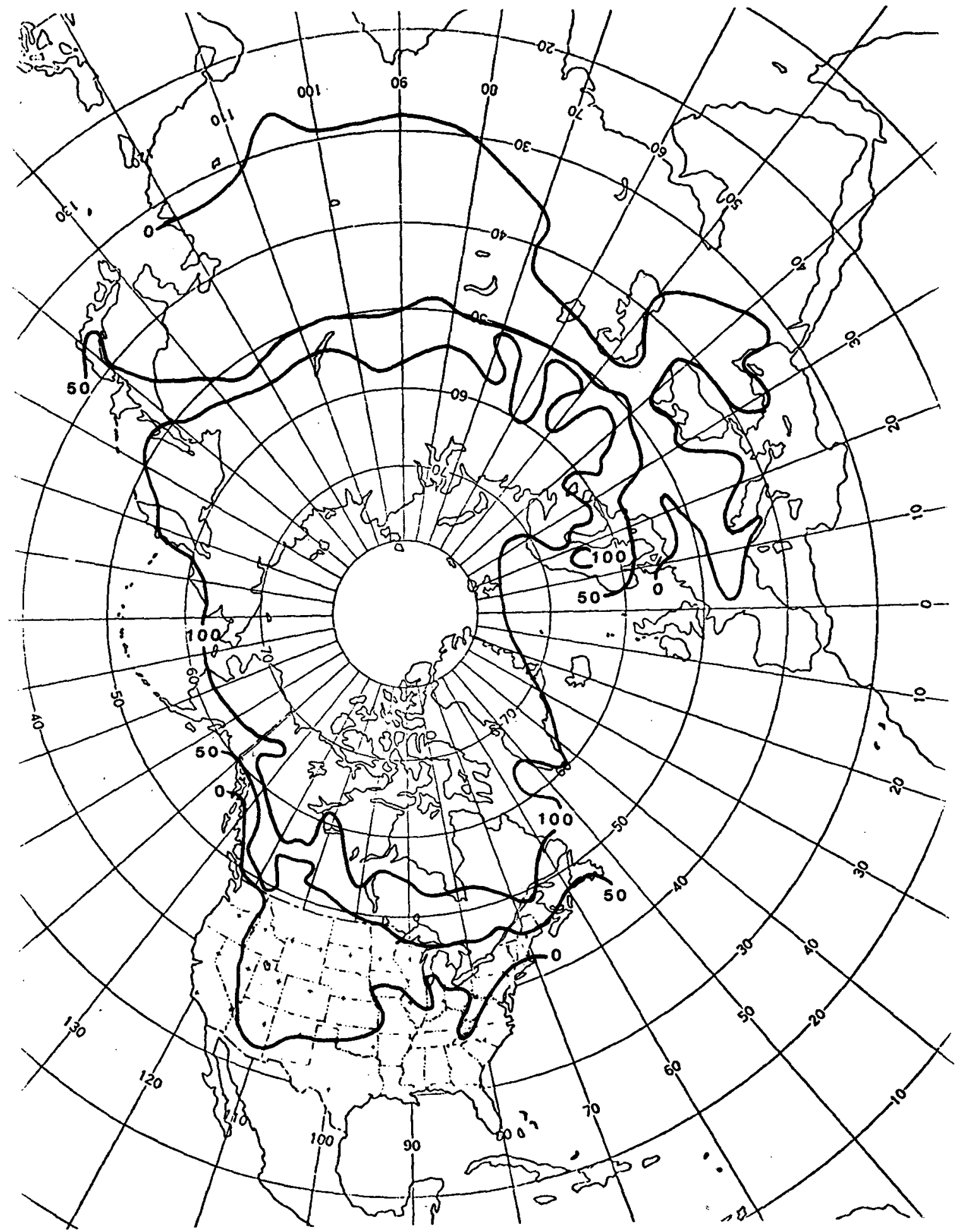

FIG. 7. (Continued)

\section{Summary and conclusions}

A satellite imagery-based Northern Hemisphere weekly snow cover data base was created, starting with
November 1966. These snow cover data were mapped and subsequently rendered into a digitized format. This procedure allowed the mathematical manipulation of the snow cover maps in order to create the first hemi- 


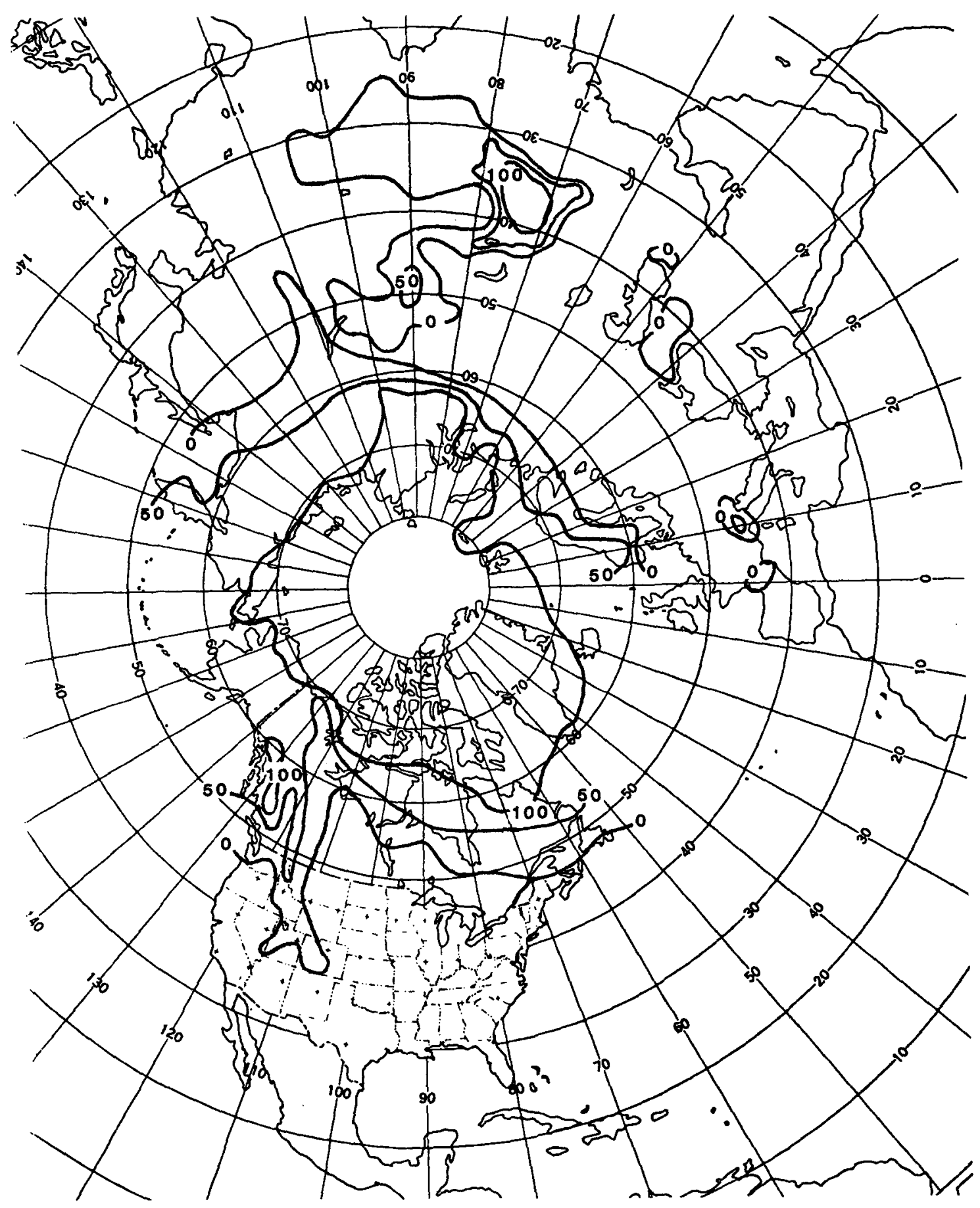

FiG. 8. As in Fig. 4, except for the end of May.

spheric, spatially data-continuous climatologies of snow cover. It was the purpose of this paper to analyze several of these new snow cover climatologies in conjunction with several established or traditional snow cover climatologies.
An annual snow cover frequency map for North America was created and compared to two frequently referenced (Lamb, 1972 and WMO, 1975) climatologies. There was general similarity between the three snow cover frequencies when comparing the southern 


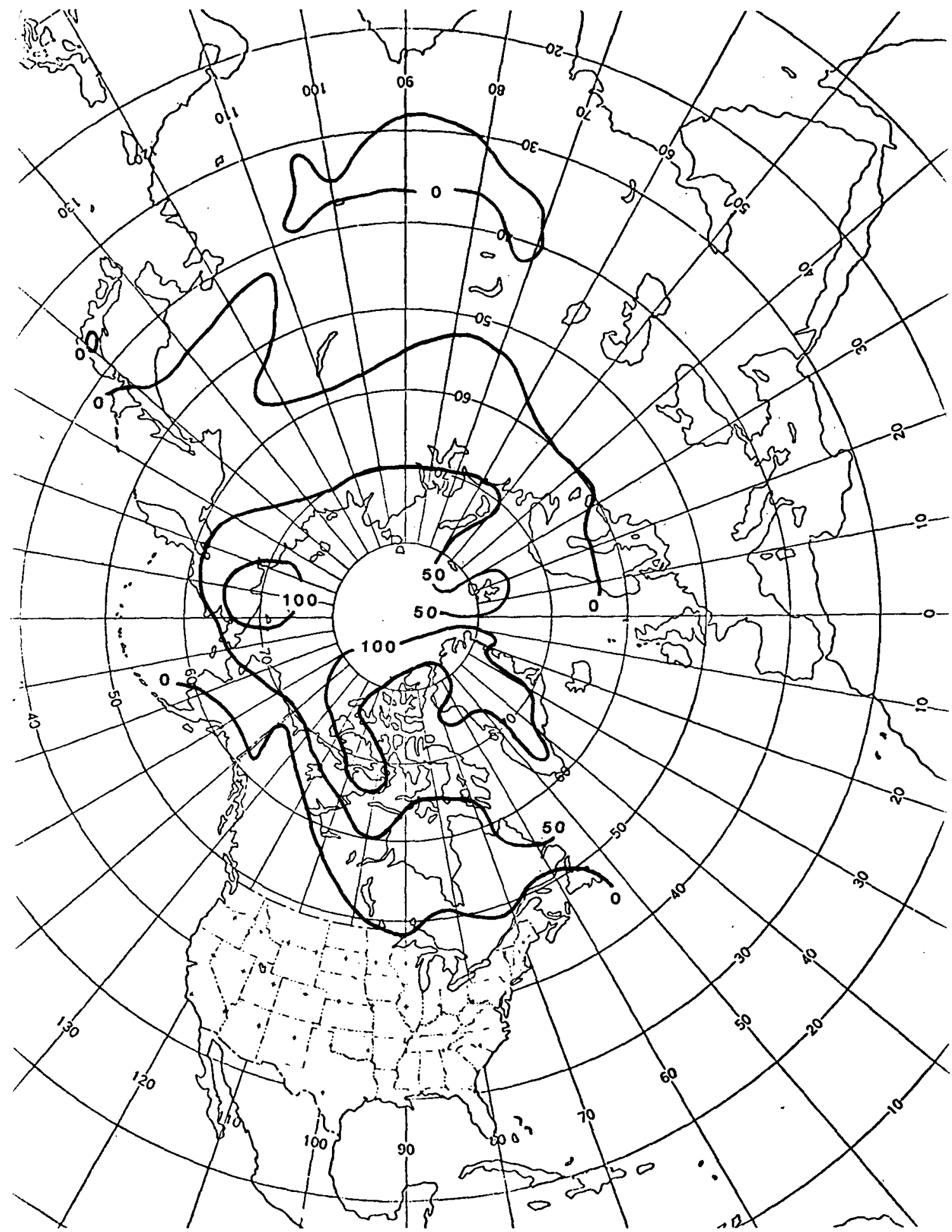

FIG. 8. (Continued) 
extent of the snow cover probability. The most obvious difference between the three climatologies was the increased detail in the mountainous region of North America and Asia, as illustrated in the satellite-derived climatology.

Monthly snow cover climatologies were created from the digitized archive of satellite-based snow cover and compared to one of the most frequently referenced monthly snow cover climatologies (Dickson and Posey, 1967). Recognizing that the earlier climatology was based upon a completely different (and globally variable) time period as well as point observations, there were still some interesting differences between these two climatologies. Five months spanning the snow cover "season" or "year" were included in the comparison.

It appears that the onset of the snow cover season in both Asia and North America during the last two decades has been delayed by several weeks when compared to the earlier climatologies. However, caution must be exercised in the interpretation of autumn snow cover due to cloud-related satellite analysis problems which can occur during that time of year. The largest contrast occurred with a $10^{\circ}$ latitudinal difference in North America. Another striking contrast in this comparison, and in all of the other monthly maps, except to a lesser degree in January, was the increased detail available for the satellite-derived data analysis in the regions of higher elevation. This is especially noted in the area centered at $35^{\circ} \mathrm{N}$ and $75^{\circ} \mathrm{E}$. High elevation detail was also considerably better in North America during the beginning and end of the snow cover year. The southeastern Asia region $\left(25-40^{\circ} \mathrm{N}\right.$ and $100-$ $120^{\circ} \mathrm{E}$ ) varied considerably between both climatologies, indicating either incompatible data or a climatic variation in the thermal/precipitation regime of this area.

Consistent throughout the maps created from the digitized satellite data was both a northward shift of the southern boundary of snow cover, and a southward shift of the region of $100 \%$ snow cover frequency. In essence, the snow transition zone ( $0-100 \%$ frequency) is narrower by $25-50 \%$ in its latitudinal extent.

It has been suggested that variations in the temporal and spatial extent of snow cover should be a good indicator of short-term climatic variation or change. As the archive of snow cover data grows (it is currently available in magnetic tape format with anticipated annual updates through the World Data Center A for Glaciology, Snow, and Ice, located in Boulder, Colorado) its potential for use in meteorological and climatic research will continue to increase.

Acknowledgments. This research effort was partially supported by a grant from NOAA/NESDIS in Washington, D.C. and the Research Council of the University of Nebraska. Appreciation is extended to Mr.
Richard Heim, who was an integral part of the digitization process, and Mr. Michael Matson who has provided technical advice/assistance from within NOAA/ NESDIS.

\section{REFERENCES}

Baldwin, T., 1985: Northern Hemisphere snow and ice chart of NOAA/NESDIS. Glaciological Data Rep. GD-18, World Data Center A for Glaciology, U. of Colorado, 109-114.

Dewey, K. F., and R. Heim, 1982: A digital archive of Northern Hemisphere snow cover, November 1966-December 1980. Bull. Amer. Meteor. Soc., 105, 1594-1597.

Dey, B., and O. Kumar, 1982: An apparent relationship between Eurasian spring snow cover and the advance period of the Indian summer monsoon. J. Appl. Meteor., 21, 1929-1932.

Dickson, R. R., and J. Namias, 1976: North American influence on the circulation and climate of the North Atlantic sector. Mon. Wea. Rev., 104, 1255-1265.

- - and J. Posey, 1967: Maps of snow cover probability for the Northern Hemisphere. Mon. Wea. Rev., 95, 347-353.

Heim, R., and K. F. Dewey, 1984: Circulation patterns and temperature fields associated with extensive snow cover on the North American continent. Physical Geography, 4, 66-85.

Kukla, G., and J. Gavin, 1983: Recent fluctuations of Northern Hemisphere snow cover in Autumn. Proc. of the Eighth Annual Climate Diagnostic Workshop, NOAA, 289-296.

__ Hemisphere. Science, 183, 709-714.

- - and D. Robinson, 1979: Accuracy of snow and ice monitoring World Data Center A for Glaciology, Glaciological Data Rep. GD-5, 91-98.

Lamb, H. H., 1955: Two-way relationship between the snow or ice limit and 1000-500-mb thicknesses in the overlying atmosphere. Quart. J. Roy. Meteor. Soc., 81, 172-189.

- 1972: Climate: Present, Past and Future, Vol. 1; Methuen and Co., Ltd.

Lockwood, J. G., 1979: Causes of Climate; Edward Arnold Ltd.

Matson, M., and D. R. Wiesnet, 1981: New data base for climate studies. Nature, 289, No. 5797, 451-456.

,-- C. P. Berg and E. P. McClain, 1979: New data and new products: The NOAA/NESS continental snow cover data base. Proc. of the Fourth Annual Climate Diagnostics Workshop, NOAA, 351-364.

Namias, J., 1960: Snowfall over eastern United States: Factors leading to its monthly and seasonal variations. Weatherwise, 13, 238247.

- 1962: Influence of abnormal surface heat sources and sinks on atmospheric behavior. Proc. of the International Symposium on Numerical Weather Prediction in Tokyo, Meteor. Soc. of Japan, 615-627.

__ 1963a: Large-scale air-sea interactions over the North Pacific from summer 1962 through the subsequent winter. J. Geophys. Res., 68, 6171-6186.

___, 1963b: Surface-atmosphere interactions as fundamental causes of drought and other climatic fluctuations, Arid Zone Research $\mathrm{XX}$, Changes of Climate, Proc. of Rome Symposium UNESCO and $W M O, 345-359$.

- 1966: Large-scale air-sea interactions as primary causes of fluctuations in prevailing weather, Transactions of the New York Academy of Sciences, SER. II, 29, 183-191.

- 1978: Multiple causes of the North American abnormal winter of 1976-77, Mon. Wea. Rev., 106, 279-295.

- 1985 : Some empirical evidence for the influence of snow cover on temperature and precipitation. Mon. Wea. Rev., 113, 15421553.

World Meteorological Organization, 1975: The physical basis of climate and climate modeling. GARP Publications Series No. 16 , $265 \mathrm{p}$. 